\title{
Review on the Effects of Combined Pollution of Lead and Chromium on Soil Microorganisms and Treatment Methods
}

\author{
Guangyao Yang, Hongsheng Wu, Xiaoling Ma, Yujie Tang, Jia Li, Yao Chai, Chaomin Wang, \\ Haichao Yang
}

Department of Agricultural Resources and Environment, School of Applied Meteorology, Nanjing University of Information Science and Technology, Nanjing, China

Email: yangguangyao95@126.com

How to cite this paper: Yang, G. Y., Wu, H. S., Ma, X. L., Tang, Y. J., Li, J., Chai, Y., Wang, C. M., \& Yang, H. C. (2020). Review on the Effects of Combined Pollution of Lead and Chromium on Soil Microorganisms and Treatment Methods. Journal of Geoscience and Environment Protection, 8, 140-150.

https://doi.org/10.4236/gep.2020.89009

Received: May 18, 2020

Accepted: September 22, 2020

Published: September 25, 2020

Copyright $\odot 2020$ by author(s) and Scientific Research Publishing Inc. This work is licensed under the Creative Commons Attribution International License (CC BY 4.0).

http://creativecommons.org/licenses/by/4.0/

\begin{abstract}
Heavy metals $-\mathrm{Pb}$ and $\mathrm{Cr}$ are important causes of environmental pollution, and they often coexist in nature. At present, the effects of $\mathrm{Pb}$ and $\mathrm{Cr}$ toxicity on soil microorganisms have been less studied, in soil environment which is extremely complex. Simulating soil environment and studying microbial reaction under various heavy metal conditions are of great significance for revealing microbial tolerance to heavy metals. In this paper, firstly, the related concepts of soil rechecking pollution are discussed, and the physical and chemical properties and forms of lead and chromium are introduced accordingly. Secondly, the effects of combined pollution of lead and chromium on soil microbial biomass, soil microbial community structure and soil microbial activity were discussed. Finally, the relevant treatment methods of heavy metal contaminated soil were put forward.
\end{abstract}

\section{Keywords}

Compound Pollution, Heavy Metals, Soil Microorganisms

\section{Introduction}

For more than 60 years, China's heavy industry has made significant contributions to China's economic development. However, behind the booming economy and industry is the increasing destruction of the natural environment year by year and the continuous deepening of pollution. As one of the most important forms of pollution caused by industrial pollution (Li et al., 2018; Fan, 2011), heavy metal pollution is seriously affecting all aspects of human living environment. At present, more than 20 million. $\mathrm{hm}^{2}$ of arable land in China has been 
polluted by heavy metals (Duan et al., 2014a; Deng, 2016; Li et al., 2005). Among them, about 3.33 million $\cdot \mathrm{hm}^{2}$ of arable land has reached medium and severe pollution, and no more cultivation is possible. The annual economic loss of crops caused by excessive heavy metals in China has reached 20 billion yuan (Duan et al., 2014b; Xu et al., 2018). The accumulation of heavy metals in the soil can lead to a decrease in soil fertility and deterioration in texture. In addition, with the leaching effect, the heavy metal ions accumulated in the soil will run off from the surface, and then enter the groundwater, polluting freshwater resources, causing the water body in the area to deteriorate and be difficult to control. Eventually it will be enriched to the human body through the food chain and food web, endangering human life and health (Xia et al., 2016; Li et al., 2013). In the world, Jafari et al. (2018) review the prevalence of rice contamination to heavy metals in Iranian grown and imported rice brands by conducting a systematic review and assess the related human health risk and found that multiple keywords such as "rice, heavy metals, and Iran" were used to search in related databases. Fractionation of heavy metals ( $\mathrm{Cd}, \mathrm{Co}, \mathrm{Cr}, \mathrm{Cu}, \mathrm{Fe}, \mathrm{Mn}, \mathrm{Ni}, \mathrm{Pb}$ and $\mathrm{Zn}$ ) was studied using modified Community Bureau of Reference sequential extraction procedure in the sediments collected at eight sites from a freshwater lake, Pakistan (Saleem et al., 2018). Defarge et al. (2018) studied the toxicity of formulants and heavy metals in glyphosate-based herbicides and other pesticides, and found that $\mathrm{Pe}$ troleum-based compounds in herbicides were highly more toxic than glyphosate. In addition, there are also related studies on the role of heavy metals in space weather, the spectral model for heavy nuclei is developed (Fu et al., 2020).

With the extensive use of fertilizers and pesticides, the discharge of industrial wastes and the increase of sewage irrigation, the interaction between pollutants and elements in soil environment becomes more complex, which leads to the increasingly serious combined pollution of heavy metals. Therefore, the study of heavy metal compound pollution is far more valuable than that of single factor pollution. In this paper, firstly, the related concepts of soil rechecking pollution are discussed, and the physical and chemical properties and forms of lead and chromium are introduced accordingly. Secondly, the effects of combined pollution of lead and chromium on soil microbial biomass, soil microbial community structure and soil microbial activity were discussed. Finally, the relevant treatment methods of heavy metal contaminated soil were put forward.

\section{The Concept of Soil Compound Pollution}

In the same environmental medium or the same branch of the ecosystem, the joint effect between two or more environmental pollutants with different properties is called compound pollution. Compound pollution must have three basic conditions at the same time: first, more than one chemical pollutant must enter the same environmental medium or the same branch of the ecosystem at the same time; second, between the chemical pollutant and the organism or various chemical pollutants there should be interactions; third, organisms should have three stages of physical chemical and chemical processes, physiological and bio- 
chemical processes, biological poisoning or detoxification adaptation processes after being stressed by pollutants. Compound pollution can usually be classified according to the source, nature and impact of the pollutant.

\subsection{According to the Source of Pollutants}

Homogenous compound pollution: Compound pollution is formed by the interaction of various pollutants existing in the same environmental medium (soil, water body and atmosphere). According to different environmental media, it can be further divided into soil composite pollution type, water composite pollution type and air composite pollution type. Homologous compound pollution is the main direction of current compound pollution research.

Heterogeneous composite pollution: formed by different pollutants or the same pollutants from different environmental media sources, it can be further divided into soil-atmosphere composite type, soil-water composite type, atmosphere-water composite type and atmosphere-soil-water complex (Zhuang, 2007).

\subsection{According to the Types of Pollutants}

Organic compound pollution: Compound pollution is formed by two or more organic pollutants coexisting. The current research focuses on compound pollution between pesticides or between pesticides and other organic pollutants.

Inorganic compound pollution: Compound pollution is formed by the interaction of two or more inorganic pollutants. The focus of current research on inorganic compound pollution is the compound pollution formed between heavy metal elements or between heavy metals and other inorganic pollutants.

Organic-inorganic compound pollution: Compound pollution is formed by inorganic pollutants and organic pollutants existing in the same environment at the same time, mainly concentrated in the compound pollution between heavy metals and antibiotics, pesticides, detergents, petroleum hydrocarbons.

\subsection{According to the Compound Pollution Effect}

Simple and similar effects: also known as dose increase, relative dose increase and similar combined effects. There is no mutual use of this effect, and there is no interaction between single pollutants. All pollutants have the same mechanism and mode of action, but with different strengths. If one pollutant replaces another pollutant in a certain proportion, the compound pollution effect will not change.

Independent joint effect: also called superposition effect, simple independent effect or simple dissimilar effect. There is no interaction between such effects, but due to the different modes of action, mechanism and location of the pollutants, when one pollutant enters the environment and interacts with the organism, resulting in a decline in the body's resistance, if another pollutant also enters the environment and interacts with the same organism, its pollution effect will be significantly enhanced.

Interaction: There is interaction between pollutants, and the combined effect 
produced by pollutants is greater or less than the sum of the effects produced by each single pollutant. When the combined effect is enhanced, it is called synergy, enhancement, or super-additive effect; in turn, it is called antagonistic, inhibitory, or subadditive (Wang et al., 2018; Meng et al., 2019).

In short, the combined effects can be divided into three actions according to their effects: superposition, synergy and antagonism. But strictly speaking, there is no absolute superposition effect of compound pollution, which will inevitably produce a synergistic or antagonistic effect. Therefore, interaction is more common in compound pollution and is the top priority of current compound pollution research.

\section{Physical and Chemical Properties and Action Mechanism of Lead and Chromium}

\subsection{Physical and Chemical Properties and Morphology of Lead}

Lead (Plumbum, $\mathrm{Pb}$ ), atomic weight 207.2, atomic number 29, is a heavy metal. The color of lead itself is bluish white. The density is $11.3437 \mathrm{~g} / \mathrm{cm}^{3}$, the melting point is $327.502^{\circ} \mathrm{C}$, and the boiling point is $1749^{\circ} \mathrm{C}$. Common valences are 0 and +2 , and the first ionization energy is 7.4167 electron volts. The second ionization energy is 15.874 electron volts. $\mathrm{Pb}$ has four stable isotopes: lead 204, 206, 207, 208. $\mathrm{Pb}$ has many valuable physical and chemical properties, such as good ductility and flexibility, strong chemical stability, and strong corrosion resistance. Generally, a dense protective layer will be formed on the surface of lead in the air, which can prevent further oxidation of lead (He et al., 2001).

\subsection{Physical and Chemical Properties and Morphology of Chromiums}

Chromium (Cr), atomic weight 51.996, atomic number 24, is a heavy metal. The color of chrome itself is steel gray. The density is $7.19 \mathrm{~g} / \mathrm{cm}^{3}$, the melting point is $1857.0^{\circ} \mathrm{C}$, and the boiling point is $2672.0^{\circ} \mathrm{C}$. Common valences are $+2,+3$, and +6 , the first ionization energy is 6.771 electron volts, and the second ionization energy is 16.508 electron volts ( $\mathrm{Hu}$ et al., 2018). There are four stable isotopes of Cr: chromium 49,50,51,52,53,54, 55. Cr has many valuable physical and chemical properties, such as good ductility, strong chemical stability, and strong corrosion resistance. Generally, a dense protective layer is formed on the surface of chromium in the air to prevent further oxidation of lead. Chromium in the soil usually exists in two ways: $\mathrm{Cr}$ (VI) and $\mathrm{Cr}$ (III). In addition, there are various combinations of chromium in the soil (Xu et al., 2002).

\section{Effect of Combined Pollution of Lead and Chromium on Soil Microorganisms}

\subsection{Effect of Heavy Metal Pollution on Soil Microbial Community Structures}

A large number of studies have proved that the soil contaminated by heavy met- 
als has significant changes in the microbial community structure. The decrease in microbial diversity caused by heavy metal pollution may be due to the decrease in the types of unsuitable species and the increase in the number of species that can adapt to the environment under the action of heavy metal stress. Kelly equaled the soil microbial community under lead contamination by LIOLOG microplate counting method. The study found that the structure and functional diversity of soil microbial communities will be affected by lead and chromium pollution. Severe heavy metal pollution will lead to a reduction in the number of microorganisms that can use the relevant carbon substrate, reduce the ability of microorganisms to use on a single carbon source substrate, and reduce the diversity of soil microorganisms.

Pennanen et al. (1996) used PLFA analysis method to study the long-term lead and chromium contaminated soil. The results show that heavy metal pollution significantly reduces the proportion of fungal characteristic fatty acids. Blum et al. (2001) discovered by polymerase chain reaction-DGGE that chromium pollution changed the soil microbial community structure and reduced microbial diversity.

\subsection{Impact of Heavy Metal Pollution on Soil Microbial Biomass}

For Impact on microbial biomass carbon, soil microbial biomass carbon, as a nutrient pool of plants and animals in the soil, plays a vital role in the sustainable development of ecosystems. It is considered as a sensitive indicator of microbial changes in soil contaminated by heavy metals, and has been widely used for soil quality evaluation. High concentrations of heavy metals have a harmful effect on all organisms including microorganisms. Long-term exposure to heavy metal contaminated soil, the growth and survival of microorganisms will be affected by different levels according to the concentration of heavy metals (Zhang et al., 2019).

In the past decade, more and more scholars began to pay attention to the impact of heavy metals' potential toxicity on the degradation of the natural environment. The research results of some scholars show that the low concentration of heavy metal pollution can significantly stimulate the growth of microorganisms and increase the biomass of soil microorganisms. Under the stimulation of different concentrations of heavy metals, the biomass carbon in the sandy loam increased more obviously, and the loam and clay increased relatively less (Chen et al., 2015).

This may be due to the simultaneous addition of organic carbon and nutrients in the sludge. However, when pollutants containing higher concentrations of heavy metals were applied to the soil or pollutants such as sludge containing heavy metals for a long period of time, the soil microbial biomass carbon did not continue to increase, but there was a significant decrease. This situation occurs because microbes have different sensitivities to heavy metal toxicity, and changes in microbial population viability or competitiveness will lead to gradual changes in population numbers. 
The above studies mainly involved the toxic effects of heavy metals in sludge on soil microorganisms. In addition, some studies have revealed the impact of heavy metal pollution caused by mining and smelting activities on soil microbial biomass. But the results of these investigations are contradictory. Heavy metal pollution in soil caused by sludge application, mining and smelting activities, and automobile exhaust emissions rarely leads to single heavy metal pollution, but often presents compound pollution containing two or more heavy metal elements. The relative toxicity and interaction are between the two. Therefore, people further study the effect of heavy metals on soil microbial biomass by adding heavy metals to the soil.

A large number of indoor cultivation tests and field tests of organic or inorganic heavy metal salts have shown that heavy metals have a strong toxic effect on soil microorganisms. Yoshida et al. (1994) found that when exogenous cadmium, lead and mercury were added to sandy soil, the soil microbial biomass decreased significantly. When the lead content in the soil is $20 \mathrm{mg} / \mathrm{kg}$ and the chromium content is $10 \mathrm{mg} / \mathrm{kg}$, the soil microbial biomass carbon reaches the lowest point.

For Soil microbial entropy (soil Cmic/Corg value), microbial biomass is an important biological coefficient for evaluating the functional changes of soil ecosystems contaminated by heavy metals. Under normal circumstances, there is a very close linear positive correlation between organic carbon and microbial biomass carbon in non-polluted soil, but in soil contaminated by heavy metals, the above relationship basically no longer exists. Therefore, the soil Cmic/Corg value can be used as an important indicator to evaluate the impact of heavy metal pollution on the energy and soil quality of the soil ecosystem (Pfiffner et al., 2017).

In most cases, the soil Cmic/Corg value is $1 \%-4 \%$. Many studies have shown that as the concentration of heavy metals increases, the $\mathrm{Cmic} / \mathrm{Corg}$ value in the soil shows a downward trend. In general, as the content of heavy metals increases, the $\mathrm{Cmic} / \mathrm{Corg}$ value in the soil will decrease significantly. The decrease in $\mathrm{Cmic} /$ Corg value in soils contaminated by heavy metals may be due to the low efficiency of soil microbes using carbon source substrates to synthesize microbial biomass, and more carbon source substrates are converted into energy for maintenance, resulting in soil reduction of microbial biomass. Another reason is that the rate of sulfidation of soil organic carbon is reduced, which leads to the accumulation of organic matter in the soil.

Effect of soil environmental factors on microbial biomass of heavy metal contaminated soil is also important. A series of research results show that the soil microbial biomass carbon has a very significant negative correlation with the effective heavy metal content in the soil. Therefore, it can be inferred that all factors affecting the bioavailability of heavy metals may affect the toxic effects of heavy metals on soil microbial biomass. Alloway's research pointed out that the addition of organic substances is an important factor affecting the availability of heavy metals in the soil environment and the potential toxicity of heavy metals 
(Alloway et al., 1990). However, there is also a study showing that the application of sludge or manure to the soil will not affect the content of heavy metals in the soil microbial biomass.

On the other hand, soil texture can significantly affect the toxicity of heavy metals to soil microbial biomass. The study of Dar (1996) pointed out that when $50 \mathrm{mg} / \mathrm{kg}$ chromium is added to the soil, the soil microbial biomass is significantly inhibited, and sandy loam is more inhibited than clay loam. Another test found that when $250 \mathrm{mg} / \mathrm{kg}$ of lead was added to soils with different textures, only the microbial biomass in sand was significantly reduced, and the microbial biomass in loam and clay was not reduced. However, when the lead content is $500 \mathrm{mg} / \mathrm{kg}$, the microbial biomass in all texture soils is significantly reduced, and the microbial biomass in sandy loam will be reduced by $16 \%-26 \%$ compared with clay loam.

\subsection{Effect of Heavy Metal Pollution on Soil Microbial Activity}

For Impact on soil respiration, soil respiration is one of the most commonly used microbial parameters to study the effects of heavy metal pollution on microbial activity (Chen, 2006). Soil basic respiration can reflect the soil organic carbon mineralization rate and microbial respiration activity, and is closely related to the soil environmental quality. Many studies have shown that soil basic respiration increases with the increase of heavy metal concentration, which may be due to the catabolism of microbial metabolic activity from biosynthesis to energy release under heavy metal stress.

For effect of heavy metal pollution on microbial metabolic entropy $\left(\mathrm{qCO}_{2}\right)$, Microbial metabolic entropy $\left(\mathrm{qCO}_{2}\right)$ is one of the important indicators of soil microbial activity, and is recommended as a sensitive physiological and ecological indicator reflecting heavy metal stress in soil. The soil environment is stressed or disturbed, and microbes may need more energy to maintain their survival, resulting in soil microbial metabolic activities reacting to varying degrees.

A large number of studies have shown that the metabolic entropy of soil microorganisms usually increases with the deepening of heavy metal pollution. Renella et al. Found that the metabolic entropy of microorganisms in lead-contaminated soil increased significantly. This may be because the microorganisms needed more energy to maintain their survival, or it may be because the degradation of the matrix quality led to a reduction in the metabolism efficiency of microorganisms (Renella et al., 2005).

For effect of heavy metal pollution on soil enzyme activity, soil enzyme activity is a sensitive indicator reflecting the effect of heavy metal pollution in soil. A large number of studies have shown that soil enzyme activity has a certain correlation with heavy metal pollution. Under normal circumstances, soil enzyme activity will drop sharply as heavy metal pollution increases.

Compared with non-polluted soil, the activities of dehydrogenase, protease, alkaline phosphatase and sulfate acetate were significantly inhibited. In short, the soil dehydrogenase activity, pulse enzyme activity and phosphatase activity in 
heavy metal-contaminated soil showed a downward trend, which can sensitively reflect the toxic effect of heavy metals on soil microbial activity (Zhou et al., 1985; Han et al., 2010).

The inhibitory mechanism of heavy metals on enzyme activity may be combined with the active site in the enzyme molecule-sparse groups and imidazole-containing coordination, etc. to form a more stable complex, which may be related to the competitive inhibition of the substrate or may be due to heavy metals By inhibiting the growth and reproduction of soil microorganisms, the synthesis and secretion of enzymes in the body are reduced, which ultimately leads to a decrease in soil enzyme activity.

\section{Governance Methods}

\subsection{Physical Repairs}

Physical remediation of heavy metal contaminated soil refers to the application of a single physical method to improve, in order to achieve the purpose of reducing and solidifying heavy metals in soil. Common methods include guest soil method, leaching method, solidified landfill method, heat treatment method and electric repair methods.

\subsection{Chemical Repair}

Chemical repair belongs to in-situ repair technology. It is a method to cause a series of chemical reactions of heavy metals by adding modifiers or inhibitors to the soil, so as to achieve the purpose of remediation and restoration, thereby reducing the water solubility, mobility and effectiveness of heavy metals in the soil. At present, more modifiers should be added to the soil. The ideal modifier should have the characteristics of no pollution, low cost, good effect and strong sustainability. Commonly used modifiers, such as lime, limestone powder, apatite, hydroxyapatite, calcium magnesium phosphate, etc., have a certain remediation effect on the soil.

At the same time, adding surfactants and heavy metal chelating agents can improve their performance. The research results of Cui et al. (2010) showed that adding lime, phospholime, montmorillonite and attapulgite to the soil improved the $\mathrm{pH}$ of the soil and transformed the soil copper from the highly effective exchange state of the plant to the less effective carbonic acid of the plant salt binding state, iron manganese oxide binding state and organic binding state. The high-dose lime and high-dose apatite treatments respectively reduced the antagonistic effects of exchangeable copper and heavy metals in the soil environment by $95 \% .94 .6 \%$, at the same time can reduce the toxicity of heavy metals.

For example, increasing the supply level of Ca reduces the absorption of heavy metals $\mathrm{Cd}, \mathrm{Ni}, \mathrm{Pb}, \mathrm{Zn}, \mathrm{Cr}$ by plants or alleviates the toxicity of heavy metals. Therefore, by adding calcium-containing substances to the soil, the effectiveness of some heavy metals can also be reduced. Chemical remediation is simple and easy, and industrial by-products can be used as improvers in the remediation 
process, so the cost is relatively low, and it is suitable for the remediation of large-area contaminated soil. However, a single chemical repair cannot eradicate the heavy metals in the soil. When the environmental conditions change, it may be released into the soil again, and it may have a certain impact on the microorganisms in the soil, and there are certain safety risks. Therefore, in the process of applying chemical remediation, materials with good stabilizing effect and less impact on soil ecosystem should be considered as modifiers.

\subsection{Bioremediation}

There are broad and narrow definitions of bioremediation. People usually refer to bioremediation in a broad sense, that is, application of heavy metal pollution remediation technology with organisms as the main body, reducing the content of heavy metals in the soil through their metabolic activities or by changing their morphology. Restoration technology is to reduce toxicity to achieve the purpose of restoration. Commonly used bioremediation technologies are: phytoremediation, animal repair and microbial repair.

\section{Conclusion and Recommendations}

Using physical and chemical techniques alone to repair heavy metal contaminated soil is not only expensive and difficult to use for large-scale pollution soil improvement, but it may also cause problems such as soil structure destruction, fertility degradation, and reduced biological activity. Therefore, in order to solve the problem of heavy metal pollution in the soil, the research on the heavy metal element soil eco-chemical behavior and remediation technology should be strengthened, especially for plants and microbial remediation technologies with broad application prospects, and the joint application of multiple remediation technologies should be actively explored to learn from each others' weaknesses to realize the remediation of heavy metal contaminated soil.

\section{Acknowledgements}

None.

\section{Conflicts of Interest}

The authors declare no conflicts of interest regarding the publication of this paper.

\section{References}

Alloway, B. J., Jackson, A. P., \& Morgan, H. (1990). The Accumulation of Cadmium by Vegetables Grown on Soils Contaminated from a Variety of Sources. Science of the Total Environment, 91, 223-236. https://doi.org/10.1016/0048-9697(90)90300-J

Blum, C., Stracke, F., Becker, S. et al. (2001). Discrimination and Interpretation of Spectral Phenomena by Room-Temperature Single-Molecule Spectroscopy. The Journal of Physical Chemistry A, 105, 304-313. https://doi.org/10.1021/jp0031092

Chen, A., Fu, B., Lu, Y. et al. (2015). Organic Material Input into Paddy Field to Improve 
Soil Microbial Carbon and Nitrogen and Soluble Organic Carbon and Nitrogen. Journal of Agricultural Engineering, 31, 160-167.

Chen, C. (2006). Research on the Influence of Heavy Metal Cd, Pb, Hg Pollution on Soil Microorganisms and Their Activities. Hangzhou: Zhejiang University.

Cui, H., Zhou, J., Du, Z. et al. (2010). Field Remediation of Heavy Metal Copper and Cadmium Contaminated Soil with Apatite and Other Modifiers. Soil, 42, 611-617.

Dar, G. H. (1996). Effects of Cadmium and Sewage-Sludge on Soil Microbial Biomass and Enzyme Activities. Bioresource Technology, 56, 141-145. https://doi.org/10.1016/0960-8524(95)00186-7

Defarge, N., Spiroux, D. V. J., \& Séralini, G. E. (2018). Toxicity of Formulants and Heavy Metals in Glyphosate-Based Herbicides and Other Pesticides. Toxicology Reports, 5, 156-163. https://doi.org/10.1016/j.toxrep.2017.12.025

Deng, W. (2016). Lead Contamination and Source Characterization in Soils around a Lead-Zinc Smelting Plant in a Near-Urban Environment in Baoji, China. Archives of Environmental Contamination and Toxicology, 4, 500-508. https://doi.org/10.1007/s00244-016-0317-1

Duan, D., Yu, M., \& Shi, J. (2014a). Advances in the Research on the Mechanism of Plant Absorption, Transport, Accumulation and Detoxification of Lead. Journal of Applied Ecology, 25, 287-296.

Duan, X., Liu, Y., Li, H. et al. (2014b). Effects of Combined Pollution of Perchlorate and Chromium on Soil Enzyme Activity and Microbial Quantity. Journal of Agricultural Environmental Sciences, 33, 322-331.

Fan, S. (2011). Heavy Metal Pollution and Control in Soil. Beijing: China Environmental Science Press.

Fu, S., Zhao, L. L., Zank, G. P., Wang, M., \& Jiang, Y. (2020). An ACE/CRIS-ObservationBased Galactic Cosmic Rays Heavy Nuclei Spectra Model II. Science China Physics, Mechanics \& Astronomy, 63, 100-111. https://doi.org/10.1007/s11433-019-9423-3

Han, G., Wang, B., Xu, W. et al. (2010). Effects of Combined Pollution of Heavy Metals $\mathrm{Cd}, \mathrm{Zn}, \mathrm{Cu}$ and $\mathrm{Pb}$ on Soil Microorganisms and Enzyme Activities. Journal of Soil and Water Conservation, 24, 238-242.

He, B., Yang, X., \& Wei, Y. (2001). Remediation Technology of Lead Contaminated Soil. Trace Element Science of Guangdong, 8, 12-17.

Hu, J., Meng, D., Liu, X. et al. (2018). The Effect of Long-Term Chromium Pollution on Soil Fungal Communities. Transactions of Nonferrous Metals Society of China, 28, 157-165. https://doi.org/10.1016/S1003-6326(18)64828-9

Jafari, A., Kamarehie, B., Ghaderpoori, M., Khoshnamvand, N., \& Birjandi, M. (2018). The Concentration Data of Heavy Metals in Iranian Grown and Imported Rice and Human Health Hazard Assessment. Data in Brief, 16, 453-459. https://doi.org/10.1016/j.dib.2017.11.057

Li, J., Yang, X., \& Chen, S. (2005). Effect of Lead Pollution on Microbial Activity of Blue-Purple Mud. Journal of Soil and Water Conservation, 19, 182-185.

Li, M., Wang, C., Li, R. et al. (2013). Microbial Remediation of Mercury, Lead and Chromium Contaminated Soil. Journal of Environmental Engineering, 7, 1568-1572.

Li, T., Huang, H., Peng, Y. et al. (2018). Screening and Adsorption of Lead-Resistant Microorganisms. Journal of Anhui Agricultural University, 45, 696-702.

Meng, Y., Zhang, L., Wang, L. et al. (2019). Enrichment Effect of Several Leafy Vegetables on Cd and As on Compound Contaminated Soil. Journal of Plant Nutrition and Fertilizer, 25, 972-981. 
Pennanen, T., Frostegard, A., Fritze, H. et al. (1996). Phospholipid Fatty Acid Composition and Heavy Metal Tolerance of Soil Microbial Communities along Two Heavy Metal-Polluted Gradients in Coniferous Forests. Applied and Environmental Microbiology, 62, 420-428. https://doi.org/10.1128/AEM.62.2.420-428.1996

Pfiffner, F., Prochazka, L., Peus, D. et al. (2017). A MEMS Condenser Microphone-Based Intracochlear Acoustic Receiver. IEEE Transactions on Bio-Medical Engineering, 64, 24-31. https://doi.org/10.1109/TBME.2016.2640447

Renella, G., Mench, M., Landi, L. et al. (2005) Microbial Activity and Hydrolase Synthesis in Long-Term Cd-Contaminated Soils. Soil Biology \& Biochemistry, 37, 133-139. https://doi.org/10.1016/j.soilbio.2004.06.015

Saleem, M., Iqbal, J., Akhter, G., \& Shah, M. H. (2018). Fractionation, Bioavailability, Contamination and Environmental Risk of Heavy Metals in the Sediments from a Freshwater Reservoir, Pakistan. Journal of Geochemical Exploration, 184, 199-208. https://doi.org/10.1016/j.gexplo.2017.11.002

Wang, X., Qian, J., Liu, Q. et al. (2018). Research Progress on Ecotoxicological Effects of Pesticide-Heavy Metal Lead Compound Pollution. Anhui Agricultural Sciences, 46, 21-25.

Xia, P., Wang, X., Zhang, J. et al. (2016). Passivation of Biomass Carbon on Copper, Lead and Chromium in Single and Compound Contaminated Soil. Soil Bulletin, 47, 33-37.

$\mathrm{Xu}, \mathrm{C}$., Yang, H., Huang, J. et al. (2018). Stability of Bioremediation of $\mathrm{Cu}^{2+}$ and $\mathrm{Pb}^{2+}$ Contaminated Soil. Industrial Construction, 7, 192-197.

Xu, Y., Qin, X., Liu, X. et al. (2002). Chromium Pollution and Its Ecological Effects. Environmental Science and Technology, 25, 8-9.

Yoshida, S., Patra, S. K., Takigawa, N. et al. (1994). Structure of Neutron-Deficient Pt, Hg, and $\mathrm{Pb}$ Isotopes. Physical Review C, 50, 1398-1403. https://doi.org/10.1103/PhysRevC.50.1398

Zhang, Z., Chen, S., Ren, T. et al. (2019). Effects of High-Carbon Basic Fertilizers on the Growth of Flue-Cured Tobacco and the Diversity Characteristics of Soil Microbial Carbon Metabolism. Soil and Fertilizer in China, 279, 79-86.

Zhou, L., Zhang, Z., Cao, C. et al. (1985). Heavy Metal Pollution of Soil and Soil Enzyme Activity. Journal of Environmental Science, 5, 176-184.

Zhuang, X. (2007). Research Progress on Combined Remediation Technology of Soil Compound Pollution. Journal of Ecology, 27, 4871-4876. 